\title{
Las competencias del talento humano de los martilleros en la eficiencia de las subastas en Perú
}

\author{
The human talent competitions of auctioneers in the \\ efficiency of auctions in Peru
}

\begin{abstract}
RESUMEN
El objetivo de este artículo es determinar la influencia entre el nivel de las competencias del talento humano de los martilleros y la eficiencia en las subastas, tanto en la afluencia de postores como en el nivel de precios adjudicados. Así una buena capacitación de un subastador asumirá la motivación para llevar a cabo la atracción de nuevos postores, además de la capacidad persuasiva para aumentar el precio de oferta de los oferentes para una mayor expectativa de importancia del bien subastado. Como resultado de este estudio se observa que existe una relación significativa, en términos de actitud motivadora y persuasión, como talentos notables en la eficiencia del licitador, que debe ser evaluado constantemente por la gestión institucional del Programa Nacional de Bienes Incautados (PRONABI) ${ }^{1}$.
\end{abstract}

Palabras clave: Talento-Humano; Motivación; Capacidad-Persuasiva; Subasta.

\begin{abstract}
The objective of this article is to determine the influence between the level of the human talent competences of the auctioneers and the efficiency in the auctions, both in the influx of bidders and in the level of prices awarded. Thus a good training of an auctioneer will assume the motivation to carry out the attraction of new bidders, in addition to the persuasive capacity to increase the bid price of the bidders for a greater expectation of importance of the auctioned good. As a result of this study, it is observed that there is a significant relationship, in terms of motivating attitude and persuasion, as notable talents in the efficiency of the bidder, which must be constantly evaluated by the institutional management of the National Program of Seized Assets (PRONABI).
\end{abstract}

Keywords: Talent-Human; Motivation; Capacity-Persuasive; Auction.

\section{José Carlos Tello Pérez ${ }^{a}$}

jose.tello@unmsm.edu.pe

César Astete Flor ${ }^{b}$

cesar.astete1@unmsm.edu.pe

${ }^{\text {a } U n i v e r s i d a d ~ N a c i o n a l ~ M a y o r ~ d e ~}$ San Marcos, Facultad de Ciencias Administrativas. Lima, Perú. ${ }^{\mathrm{b}}$ Universidad Nacional Mayor de San Marcos, Facultad de Ciencias Económicas. Lima, Perú.

${ }^{1}$ Antes CONABI (Comisión Nacional de Bienes Incautados).

Presentado: 02/09/2020 - Aceptado: 29/10/2020 - Publicado: 26/11/2020

(C) Los autores. Este artículo es publicado por Gestión en el Tercer Milenio de la Facultad de Ciencias Administrativas de la Universidad Nacional Mayor de San Marcos. Este es un artículo de acceso abierto, distribuido bajo los términos de la licencia Creative Commons Atribucion - No Comercia_Compartir Igual 4.0 Internacional. (http://creativecommons.org/licenses/by-nc-sa/4.0/) que permite el uso no comercial, distribución y reproducción en cualquier medio, siempre que la obra original sea debidamente citada. 


\section{INTRODUCCIÓN}

Alles (2007) define a las competencias del talento humano como "las características de personalidad, que son observados en los comportamientos de cada persona y pueden generar un desempeño exitoso en un puesto de trabajo" (p. 79). Con esta definición deberían operar todas las entidades del Estado, ante una nueva gestión de los servidores y personal público. Sin embargo, la mayoría de las instituciones del estado no propician el desarrollo del talento y las competencias en los trabajadores. Una de estas instituciones es el Programa Nacional de Bienes Incautados (PRONABI) que no es la excepción, pues no cuenta con talleres, políticas ni reglamentos que acrediten la participación de los trabajadores en algún evento de gestión o desarrollo de competencias humanas.

En ese sentido, las subastas públicas orientadas a generar ingresos al Estado, por la incautación de bienes ilícitos, debe tener los subastadores altamente competitivos; por este motivo la institución encargada capacita a su personal en dos competencias importantes para la realización de la eficiente labor del martillero: capacidad persuasiva y motivación. El primero, en la concepción de mercadotecnia, es aprehender la conciencia de las personas para que compren un determinado bien o servicio, por lo que es parte del buen desempeño de un subastador. Si bien Petty y Cacioppo (1986) en su "Modelo de la probabilidad de elaboración" reconocen que el éxito de la persuasión depende del grado de motivación y capacidad de atención del receptor para desear algo. El segundo, menciona Reeve (2010) que desde las teorías de Maslow (1991) hasta Robbins y Judge (2009), definen la motivación como "los procesos que inciden en la intensidad, dirección y persistencia que realiza un individuo en la consecución de un objetivo" (p. 28).

Así, en las subastas de PRONABI se puede observar que los subastadores (o martilleros) sólo se limitan a mencionar las ofertas más altas hacia los postores, sin ningún tipo de incentivo para mejorarlas, una falta de persuasión para levantar el precio de la "puja" restringiendo un mayor nivel de ingresos que podría percibir la institución. Sin embargo, la falta de capacidad persuasiva por parte de los martilleros no es la única razón que perjudica intrínsecamente las pretensiones económicas de PRONABI; también está la ausencia de estrategias motivacionales, tales como las recomendadas por la teoría "Y", que se observa mediante la falta de nivel de motivación del empleado (martillero), lo cual, según Coulter (1996), citado en Chiavenato (2004), reduce su esfuerzo para alcanzar el propósito económico de la organización, como es el máximo nivel de recaudación. Evidentemente la intensidad y persistencia del esfuerzo, se debería ver reflejado en la conducta del martillero.

Por tanto, si el martillero muestra una conducta o actitud poco entusiasta o dinámica (como ocurre con los martilleros del PRONABI), el público (postores), producto del efecto contagio, sentirá el mismo malestar y aburrimiento, desincentivando su participación en los próximos eventos, provocando así (en muchos casos) la participación de sólo un postor y, por tanto, de acuerdo con las bases de la Subasta de PRONABI, la adjudicación al precio base.

Muchos autores consideran que el nivel de las competencias del talento humano (es decir, las enlazadas con la personalidad y el comportamiento) obtienen un vínculo muy cercano con la capacidad de hacer eficazmente las tareas del trabajo que se le asigna, por tanto, es influyente en el bienestar de la organización. Producto de ello, es que el desarrollo de la teoría se centró en cómo lograr una óptima selección del personal y cómo desarrollar sus competencias al interior de la institución.

\section{Nociones Actuales de la Gestión de Recursos Humanos.}

La gestión del talento humano, en la mayor parte del mundo occidental donde las empresas pretenden adquirir desde diferentes ópticas, la exigencia de una renovación y mejora de algunos principios esenciales en esta área muy importante. Según Lefcovich (2009) algunos paradigmas actuales en esta gerencia que se manejan actualmente para que las empresas sean más competitivas son:

- Todo el personal colabora para alcanzar los objetivos organizacionales, contribuyendo de manera activa con la calidad de su trabajo.

- La motivación laboral debe ir asociado con los conocimientos técnicos y el potencial 
creativo para estimular la innovación en la organización.

- Impulsar el trabajo en equipo en toda la organización.

- Darle trascendencia a la capacitación del personal para descartar que es una inversión.

Actualmente, en el Perú, la mayoría de las instituciones estatales persisten en continuar con aquellas condiciones totalmente opuestas a las definidas en los puntos anteriores. Por ello, se tiene la necesidad urgente de efectuar un cambio de mentalidad y actualización de estos paradigmas para alcanzar una ventaja competitiva en la organización. Las empresas que sigan considerando de forma opuesta a lo que la mayoría realiza, obtendrá ventajas absolutas y relativas de manera notable, para implementar acciones que mejoren su performance y lleguen ser únicas en el mercado.

Estos cambios no solo modifican la mentalidad de la clase dirigencial, sino que también genera estrategias y tácticas que favorecen a la competitividad de los recursos humanos en la compañía. Para realizar estas mejoras es necesario orientar la gestión de recursos humanos a los cambios de mentalidad relativos a ella, pues se basan en modificaciones de los fines estratégicos para apoyar a los trabajadores en sus logros laborales como personales, en cuestiones comerciales, tecnológicas y financieras.

Diversos investigadores en psicología $\mathrm{y}$ potencial innovador han deducido que las personas emplean $1 \%$ de sus capacidades en promedio. Según Lefcovich (2009) si el crecimiento en la productividad, tanto a nivel empresarial como social, fuera mejor aprovechado se alcanzaría "el máximo provecho a los sistemas de educación y capacitación, la eliminación de las barreras a la creatividad e innovación, el fomento de la imaginación, y la mejora en los sistemas de comunicación" (p. 25).

El principal enfoque de esta investigación es el humanista que ha encontrado su principal afinidad en las ciencias administrativas y genera una diversidad de teorías para determinar la relación existente entre las organizaciones empresariales y el talento humano; pero aún falta establecer relaciones sobre qué y cómo gestionarlos, pues a medida que avanza el tiempo, la velocidad de transmitir el conocimiento se va haciendo más consistente y por ende existen razones para seguir desarrollando nuevas investigaciones acerca de este enfoque.

\section{Enfoque Conductista.}

Para canalizar la postura de esta investigación, el enfoque conductista nos da un alcance de la gran importancia de la contratación del personal adecuado para desenvolverse en los escenarios profesionales del puesto laboral, pues se identifican las capacidades de fondo que conllevan a desempeños superiores. De acuerdo con lo que se necesita en el puesto, se adaptan a las capacidades que determinan ciertas situaciones nuevas, para lo cual es necesario que el personal tenga capacidad para una buena toma de decisiones, habilidad analítica y creatividad.

Este proceso deriva del análisis, no solo resulta de los procesos de la organización, sino también de las capacidades de las personas con sus objetivos personales y profesionales, identificación de situaciones nuevas y buena toma de decisiones. De acuerdo con Mertens (2002) el modelo conductista registra "las capacidades de fondo de la persona que conlleva a desempeños superiores en la organización. Generalmente, se aplica a los niveles directivos en la organización y se circunscribe a las capacidades que le hacen destacar ante circunstancias no predefinidas" (p. 3).

Por el contrario, de acuerdo con Tobón (2006), las competencias están ligadas a los procesos organizacionales; por lo que este enfoque se resalta en "asumir la competencia como: habilidades, conocimientos y destrezas para resolver dificultades en los procesos laborales-profesionales, desde el marco organizacional" (p. 20).

Estas competencias laborales se encuentran dentro de una serie de capacidades que en su conjunto forman el Talento Humano, que según Alles (2007) analiza las capacidades de una persona, teniendo en cuenta tres perfiles como son los conocimientos, destrezas y competencias. Los cuales se resume en la Figura 1.

Según el Manual del director de recursos humanos, realizado por Ernest y Young Consultores 


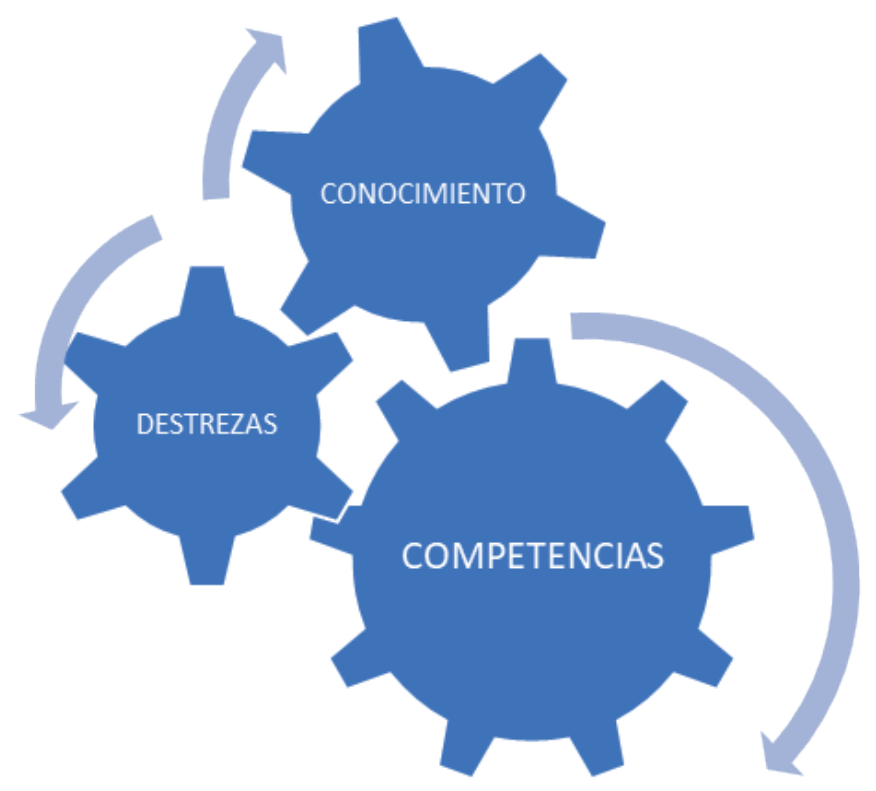

Figura 1. Competencias del Talento Humano en tres planos. Adaptado de "Desarrollo del talento humano basado en competencias", por M. A. Alles, 2007, p. 38.

(2013) las competencias son características subyacentes de la persona, "que están relacionadas con una correcta actuación en el puesto de trabajo y que pueden basarse en la motivación, en los rasgos de carácter, en el concepto en sí mismo, en actitudes y valores, y una variedad de conductas" (p. 5).

Este artículo tomará dos competencias, que son básicamente el sustento del martillero para que la subasta sea exitosa y eficiente, que genere ganancias para el Estado y sea atractivo para que más postores propongan sus ofertas. Estas competencias son motivación laboral y capacidad de persuasión.

\section{Motivación laboral.}

La motivación laboral es una estrategia que integra todo el trabajo que se realiza en las diferentes actividades laborales porque ofrece incentivos, esto ayuda a que el trabajador realice con satisfacción sus tareas. La motivación laboral depende de dos factores: cómo el trabajador se auto estimule y cómo lo estimula el entorno (Robbins y Coulter, 2008).

Entendamos entonces que la motivación se vuelve un factor importante para el comportamiento del ser humano, puesto que este, se verá involucrado en diferentes circunstancias las cuales lo llevarán a actuar de cierta forma, ya sea por decisión propia o como se mencionaba anteriormente, porque el medio así se lo solicite.

Robbins y Judge (2009) definen a la motivación como "los procesos que inciden en la intensidad, dirección y persistencia del esfuerzo que realiza un individuo para la consecución de un objetivo" (p. 175). Según estos autores, los tres elementos fundamentales en la definición anterior son intensidad, esfuerzo y persistencia. Primero, se entiende que la intensidad consiste entonces en cuanto una persona se esfuerza, es el principal elemento en el que se piensa cuando se habla de motivación. Segundo, el esfuerzo que se debe buscar es el que se dirige hacia las metas de la organización y tiene congruencia con ellas. Finalmente, la motivación tiene una inclinación de persistencia, que es la medida de cuánto tiempo una persona sostiene su esfuerzo.

La motivación es de suma importancia para las empresas, ya que Rodríguez (2002) citado por Berardi (2015) menciona esta trascendencia indicando que "el capital humano es uno de los principales elementos de las empresas. Por ello, en el desarrollo de las políticas de Responsabilidad social, las organizaciones han 
de asumir compromisos de gestión sensibles a las necesidades de sus trabajadores" (p. 15).

\section{Capacidad Persuasiva.}

Moya (1999) menciona que:

La eficacia de un mensaje persuasivo depende fundamentalmente del efecto que produzcan en el receptor cuatro elementos claves: a) la fuente (quién es el emisor del mensaje: su experiencia, sinceridad, atractivo, semejanza con el receptor, poder); b) el contenido del mensaje (calidad de los argumentos, incentivos que promete, organización, claridad, si pone el énfasis en los aspectos racionales o emocionales); c) el canal comunicativo (por ejemplo, visual o auditivo, directo o indirecto), y d) el contexto (relajado o serio, agradable o desagradable, distracciones). (p. 15) (Ver Figura 2)

McGwire (1972) citado en Morales y Huici (1989), enunció un modelo sobre la relación entre características del receptor y susceptibilidad de persuasión. Por lo que la actitud cambia cuando está determinado principalmente por la recepción del mensaje y la aceptación de este. Las personalidades del receptor, en ocasiones, toman efectos inversos sobre estos dos componentes.

Por otro lado, investigaciones actuales indican que:

El aumento de la inteligencia se presenta asociado a la disminución de la persuasión. La autoestima, por su parte, también parece estar relacionada positivamente con la recepción y negativamente con la aceptación. Cuanto mayor es el conocimiento que el receptor tiene del tema y más articulado está este conocimiento, esto es, cuanta más fuerza tiene la actitud, más difícil es persuadirle. (Morales y Huici, 1989, p.23)

\section{Persuasión y Cambio de Actitud.}

La Teoría de la Persuasión que guía los cambios de actitud de las personas, se regula en la propensión que confiere a las actitudes y sus
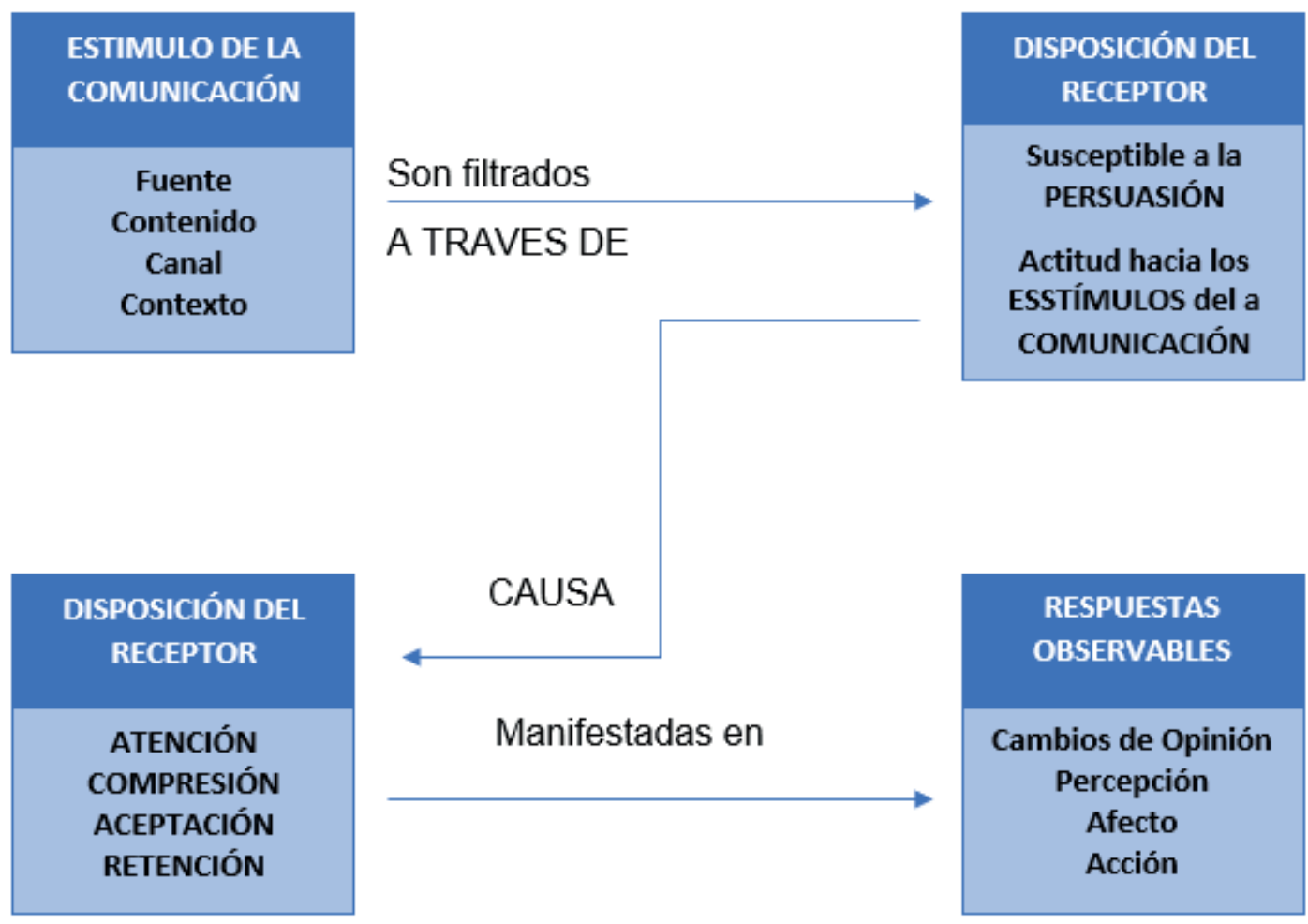

Figura 2. Elementos de la Capacidad Persuasiva. Adaptado de "Persuasion and Social Influence", por S. Trenholm, 1989, p. 155. 
mecanismos un cierto grado de predictibilidad en las acciones y conductas del ser humano. Es porque un mensaje persuasivo que pretende cambiar la actitud y la conducta tiene que modificar primeramente los pensamientos o creencias del que recibe el mensaje.

\section{Teoría de las Subastas.}

La subasta se emplea cuando un ofertante tiene muchos compradores factibles de adquirir el producto, o un demandante tiene muchos vendedores que están dispuestos a pagar por el producto. Por lo que "si desea evitar negociar con cada uno de los compradores, el vendedor puede hacer valer su posición de monopolio para imponer las reglas que han de definir con quién se transará y a cuál precio" (Singer, 2002, p. 4).

\section{Tipos de subastas.}

En este estudio se adopta el modelo clásico de subastas, que según Singer (2002) se basa en dos supuestos:

- Los postores son simétricos, es decir, la disposición probable que delimita su valoración de compra es la misma para todos.

- El valor de compra que propuso el ganador obedece únicamente a las ofertas enunciadas por los postores que ofertaron en la subasta.

\section{Licitación de sobre sellado}

En una subasta de sobre sellado, se realiza cuando dos o más postores indican de manera secreta el precio que han decidido ofertar por el bien subastado. Luego, el subastador descubre cada sobre y concede como ganador al postor que propuso la oferta más alta, si existe empate entre los postores dicha adjudicación se realiza al azar.

\section{Subasta de segundo precio o de Vickrey}

Una subasta se llama de segundo precio cuando el ganador es el oferente que ofreció el mayor precio por el bien, pero no paga el precio que él ofreció, sino la segunda oferta más alta. A modo de ejemplo, si Pedro, Juan y Diego ofrecen $\$ 30, \$ 20$ y $\$ 40$, Diego se adjudica el bien y paga $\$ 30$.

\section{Ineficiencia en Subasta.}

Según Lengwiler y Wolfstetter (2010) en una subasta existe la ineficiencia por dos tipos de corrupción: a) tipo I, puede invitar al mejor postor a reducir su oferta o b) tipo II), puede invitar al segundo mejor postor a aumentar su oferta. Esto contribuye a explicar por qué combatir la corrupción es intrínsecamente difícil. Nuestro análisis se basa en la suposición de que el subastador corrupto contempla solo un contacto ilegal. Justificamos esto con el hecho de que los esquemas de manipulación de ofertas que involucran a varios licitadores están sujetos a un mayor riesgo de detección, porque cada transferencia deja alguna evidencia sólida que puede rastrearse.

\section{Habilidades del Martillero como Meca- nismo de Eficiencia de una Subasta.}

Según Lacetera, Larsen, Pope, y Sydnor (2016) se considera seis mecanismos frecuentes que podrían impulsar la heterogeneidad en la capacidad del subastador:

- Revelación directa de información. Una forma en que los subastadores podrían afectar los resultados del mercado es revelando directamente información sobre los productos que se venden.

- Persuadir a los vendedores para que disminuyan los valores de reserva. Los principales efectos documentados en este documento se refieren a la capacidad de un subastador para lograr una venta.

- Generación de patrones de ofertas que aumentan la revelación de los valores del licitador. Es posible que las subastas del mundo real no logren los mismos beneficios para aumentar los ingresos que la teoría clásica predeciría.

- Reducción de las fricciones de búsqueda. Gran parte de la actividad en las subastas de automóviles al por mayor ocurre en una variedad de carriles de subastas simultáneamente.

- Facilitar la negociación eficiente directamente o mediante ofertas fantasmas. Un subastador podría facilitar la negociación entre el mejor postor y el vendedor si la 
oferta final no alcanza el precio de reserva secreto del vendedor. Así, el subastador actúa como si el postor final aún enfrentara una corriente de ofertas competidoras, lo que indica al postor final que el precio de reserva aún no se ha alcanzado.

- Explotación de sesgos de comportamiento. Una fuente final de heterogeneidad puede provenir de la variación en la capacidad que tienen los subastadores de explotar los posibles sesgos de comportamiento en la configuración de la subasta.

\section{MÉTODOS}

Este estudio es de tipo aplicada, ya que se busca el empleo de una teoría en la solución de un problema. Además, la investigación tiene un nivel descriptivo, pues se describe un problema, se analiza a través de un instrumento para dar una recomendación acertada. El método de investigación a emplear de acuerdo con Sierra (2001) será el deductivo, puesto que "los conceptos y enunciados surgen de una revisión y sistematización presentada en el marco teórico; a partir del cual se realiza la contrastación empírica en una realidad concreta" (p. 21).

De otro lado, Arias y Peñaloza (2013) muestran que "estadísticamente la adjetivación de población finita o infinita va a depender de la posibilidad del investigador de contar con un listado completo de los individuos, sujetos u objetos investigados" (p. 9). Por lo que la población se ha determinado por los 45 postores asistentes a la subasta realizada por CONABI de fecha 6 de junio del 2017, fecha en la cual se realizó la subasta pública, la cual se analizará en el presente estudio. Reemplazando en la fórmula de Fisher y Navarro (1996) obtenemos un tamaño de muestra (n) de 30 postores, los cuales se seleccionarán aleatoriamente para realizar un cuestionario que servirá de instrumento para los resultados de esta investigación.

El instrumento que se usó fue realizado por los autores y fue validada por juicio de expertos en el área de recursos humanos, igualmente se confirmó su alta confiabilidad en consistencia interna a través del Alfa de Cronbach que tuvo como resultado 0.833 , lo cual indica que el instrumento puede ser replicable y sus resultados son válidos.

Cabe mencionar que el instrumento tuvo las preguntas que miden los indicadores, los cuales brindan la percepción de los 30 asistentes al evento de CONABI, sobre las competencias humanas (primera variable) que destacan y se observan en los martilleros, además de entender con precisión su relación con la eficiencia de la subasta (segunda variable) los cuales se relacionan con sus dimensiones $\left(\mathrm{x}_{1}-\mathrm{y}_{1} ; \mathrm{x}_{2}-\mathrm{y}_{2}\right)$ como se ve en la Tabla 1. Así, las preguntas consideradas de apoyo en la primera variable son para las dimensiones motivación y capacidad persuasiva que son numeradas del 1 al 8 y, las dimensiones afluencia y ganancia en Subastas en la segunda variable son del 9 al 16. Cada pregunta específica (Ítems) poseerá 5 alternativas en escala Likert como sigue: Excelente (1), Bueno (2), Regular (3), Malo (4) y Deficiente (5); cuyos resultados se exponen en el siguiente capítulo de esta investigación.

\section{RESULTADOS}

A continuación, se hará una descripción relacional entre las dimensiones de las variables de estudio, cuyos resultados se han hallado luego de realizar el cuestionario (instrumento). Así se observa que en la Tabla 2 la relación entre la Motivación que tiene el martillero y la Afluencia de postores es positiva, es decir, si la motivación mejora, la afluencia también lo hará.

Tabla 1

Distribución de dimensiones.

\begin{tabular}{llll}
\multicolumn{1}{c}{ Variables } & \multicolumn{1}{c}{ Dimensiones } & \multicolumn{1}{c}{ Tipo de Ítem } & \multicolumn{1}{c}{ Ítems } \\
Competencias Humanas $(\mathrm{X})$ & Motivación $\left(\mathrm{x}_{1}\right)$ & Escala de Licker & 1 al 4 \\
& Capacidad Persuasiva $\left(\mathrm{x}_{2}\right)$ & Escala de Licker & 5 al 8 \\
Eficiencia de Subastas $(\mathrm{Y})$ & Afluencia $\left(\mathrm{y}_{1}\right)$ & Escala de Licker & 9 al 12 \\
& Ganancia $\left(\mathrm{y}_{2}\right)$ & Escala de Licker & $13 \mathrm{al} \mathrm{16}$ \\
\hline
\end{tabular}

Nota: Elaboración propia. 
En los resultados de la Tabla 2 indican que los indicadores de la dimensión Motivación (Intensidad, dinámica y entusiasmo) explican la Afluencia de postores, de acuerdo con la percepción que tuvieron sobre el Martillero, los cuales indican que el $20 \%$ de los asistentes a la subasta declaran a la motivación del martillero como Malo y el 80\% Regular. Además, la proporción de la afluencia de postores está influida por la motivación, el $75 \%$ de los que perciben que el martillero está regularmente motivado afirma que la afluencia es poca, y el 89\% de los que perciben que está mal motivado indica que la afluencia de postores que asisten a las subastas es regular.

En la Tabla 3 se observa que la relación entre la Capacidad Persuasiva que tiene el martillero y la Ganancia Ofertante es positiva, es decir, si la Capacidad Persuasiva mejora, la afluencia también lo hará.

En los resultados de la Tabla 3 se observa que la relación entre la Capacidad Persuasiva que tiene el martillero y la Ganancia Ofertante es positiva, es decir, si la Capacidad Persuasiva mejora, la afluencia también lo hará. Por otro lado, los indicadores de la dimensión Capacidad Persuasiva (organización, claridad y actitud) explican la Ganancia Ofertante, de acuerdo con la percepción que tuvieron sobre el Martillero, indican que el $57 \%$ de los asistentes a la subasta declaran a la Capacidad persuasiva del martillero como Regular, el 30\% lo considera Malo y el 13\%, bueno. Además, la Ganancia Ofertante está influida por la Capacidad Persuasiva, por ende, el 53\% de los que perciben que el martillero está regularmente motivado afirma que la Ganancia Ofertante es poca, el 57\% regular; además, $42 \%$ de los que perciben que el martillero está mal motivado indica que esta ganancia es poca, mientras el $11 \%$ consideran regular la Ganancia Ofertante de las subastas.

Por último, en la Tabla 4 se observa que la relación entre las variables Competencias $\mathrm{Hu}$ manas que tiene el martillero y la Eficiencia en Subasta, la cual es positiva, es decir, si la Competencias Humanas mejora, la Eficiencia también lo hará.

En los resultados de la Tabla 4 indican que las dimensiones de la variable Competencias Humanas (Motivación y Persuasión) explican la Eficiencia en Subasta, de acuerdo con la percepción que tuvieron sobre el Martillero, los cuales indican que el $63 \%$ de los asistentes a la subasta declaran a la Competencias Humanas

Tabla 2

Relación entre la Dimensión Motivación del Martillero sobre la Afluencia de postores

\begin{tabular}{llccc} 
& & \multicolumn{2}{c}{ Motivación Laboral } \\
& & Malo & Regular & Total \\
\multirow{2}{*}{ Afluencia a la Subasta } & Poca & $25,0 \%$ & $75,0 \%$ & $100,0 \%$ \\
\hline Total & Regular & $11,1 \%$ & $88,9 \%$ & $100,0 \%$ \\
\hline
\end{tabular}

Nota: Elaboración propia.

Tabla 3

Relación entre la Dimensión Capacidad Persuasiva del Martillero sobre la Ganancia

\begin{tabular}{|c|c|c|c|c|c|}
\hline & & \multicolumn{4}{|c|}{ Capacidad Persuasiva } \\
\hline & & Malo & Regular & Bueno & Total \\
\hline \multirow{4}{*}{ Ganancia Ofertante } & Muy poca & & $100,0 \%$ & & $100,0 \%$ \\
\hline & Poca & $42,1 \%$ & $52,6 \%$ & $5,3 \%$ & $100,0 \%$ \\
\hline & Regular & $11,1 \%$ & $55,6 \%$ & $33,3 \%$ & $100,0 \%$ \\
\hline & Buena & & $100,0 \%$ & & $100,0 \%$ \\
\hline Total & & $30,0 \%$ & $56,7 \%$ & $13,3 \%$ & $100,0 \%$ \\
\hline
\end{tabular}

Nota: Elaboración propia 
Tabla 4

Relación entre Variables Competencias humanas del Martillero sobre la Eficiencia

\begin{tabular}{llcccc} 
& \multicolumn{3}{c}{ Competencias humanas } \\
& & Malo & Regular & Bueno & Total \\
\cline { 2 - 5 } Eficiencia de la Subasta & Poca & $50,0 \%$ & $50,0 \%$ & & $100,0 \%$ \\
& Regular & & $88,9 \%$ & $11,1 \%$ & $100,0 \%$ \\
& Buena & & $100,0 \%$ & & $100,0 \%$ \\
\hline Total & & $\mathbf{3 3 , 3 \%}$ & $\mathbf{6 3 , 3 \%}$ & $\mathbf{3 , 3 \%}$ & $\mathbf{1 0 0 , 0} \%$ \\
\hline
\end{tabular}

Nota: Elaboración propia.

del martillero como Regular, el 33\% lo considera Malo y el 4\%, bueno. Además, la proporción de la Eficiencia en Subasta está influida por la Competencias Humanas, el 50\% de los que perciben que el martillero es competitivo malo afirma que la Eficiencia en Subasta es poca y la otra mitad regular; además, $89 \%$ de los que perciben que tiene competencias regulares indica que es regularmente eficiente, mientras el $11 \%$ consideran buena la Eficiencia en Subasta de las subastas.

\section{DISCUSIÓN}

De acuerdo con Vera (2016), se evidencia que el pago de los honorarios de un martillero es muy importante, ya que refleja una motivación que pueda hacer más eficiente al martillero en las subastas, en el resultado de esta investigación la actitud motivadora es baja, porque el pago de sus honorarios no refleja garantía, por lo que la afluencia de oferentes es escasa. Los resultados también indican que la capacidad persuasiva del $86 \%$ de los martilleros se encuentra entre regular y malo, los cuales coinciden con los trabajos de Navarrete (2014) y Vasco (2014) indicando que los martilleros en el Perú no tienen conocimiento de las normativas legales para evitar violar la seguridad jurídica de las subastas, eso también muestra la poca capacitación de los subastadores.

Por otro lado, los resultados indican que el nivel de difusión de las subastas es malo, coincidiendo con Alfaro (2010) quien afirma que el $86 \%$ de los oferentes a una subasta en Lima son personas naturales.

Además, Lengwiler y Wolfstetter (2010) indican que la corrupción no solo redistribuye el excedente del vendedor, sino que también distorsiona la eficiencia. Como podemos analizar en nuestros resultados, la percepción que tiene los ofertantes en la eficiencia de las subastas es regular, por lo que se podría caer en una ineficiencia tipo 2 en subastas.

\section{CONCLUSIONES}

- El nivel de las competencias del talento humano de los subastadores influye de manera positiva y significativamente, expresado con una relación media alta de 53\%, sobre la eficiencia de la subasta de bienes decomisados organizada por PRONABI.

- Se ha podido constatar que la falta de una actitud motivadora por parte del subastador genera, de acuerdo con lo expresado por Mandino (1988), un efecto contagio en los asistentes, los cuales ya no asistirían al evento haciendo una menor afluencia de postores a una subasta organizada por PRONABI. En conclusión, se halla una falta evidencia estadística $(\alpha=0.338>0.05)$ para asegurar que esta sea la principal causa de la poca afluencia de postores al evento, con una relación baja de 18\%.

- La falta de Capacidad persuasiva tienen una influencia no significativa en las ganancias adquiridas en subastas organizadas por PRONABI, pues no alcanza la evidencia estadística $(\alpha=0.056>0.05$, con relación media de $35 \%$ ) el cual inclusive los postores, en su mayoría, manifiestan que es poco claro en su exposición, socava la posibilidad de poseer el poder de negociación en la subasta y adjudicar a un precio relativamente elevado, generando una reducción del precio base para el siguiente evento. 


\section{REFERENCIAS BIBLIOGRÁFICAS}

Alfaro, T. (2010). Evaluación de las actividades realizadas por los martilleros públicos en los remates judiciales de bienes inmuebles, en La Corte Superior De Justicia de Lima, el año 2007 (Tesis de Magíster en Derecho con mención en Derecho Civil y Comercial). Universidad Nacional Mayor de San Marcos, Lima.

Alles, M. A. (2007). Desarrollo del talento humano basado en competencias. Buenos Aires, Argentina: Granica S.A.

Arias L., S., y Peñaloza, M. (2013). Muestreo enfoque ilustrado para investigar. Mérida: Talleres Gráficos de la Universidad de Los Andes.

Berarti, A. (2015). Motivación laboral y Engagement. Argentina: Universidad Fasta.

Chiavenato, I. (2004). Introducción a la Teoría General de la Administración. Bogotá, Colombia: Mc Graw Hill.

Ernest \& Young Consultores. (2013). Manual del Director de Recursos Humanos. Londres, Inglaterra: Ernst \& Young Consultores.

Fisher, L., y Navarro, A. (1996). Introducción a la Investigación. Ciudad de México, México: McGraw Hill.

Lacetera, N., Larsen, B. J., Pope, D. G., y Sydnor, J. R. (2016). Bid Takers or Market Makers? The Effect of Auctioneers on Auction Outcome. American Economic Journal: Microeconomics, 8(4), pp. 195-229.

Lefcovich, M. (2009). Seis SIGMA hacia un nuevo paradigma en gestión. Santa Fe, Argentina: El Cid Editor.

Lengwiler, Y., y Wolfstetter, E. (2010). Subastas y corrupción: un análisis de la manipulación de ofertas por un subastador corrupto. Revista de Dinámica Económica y Control, 34(10), pp. 1872-1892.

Mandino, O. (1988). El vendedor más grande del mundo. México D. F.: Editorial Planeta Mexicana SA.

Maslow, A. (1991). Motivación y Personalidad. Madrid, España: Ediciones Diaz de Santos S.A.

Mertens, L. (2002). ISO 9000:2000 y Competencia laboral: El aseguramiento del aprendizaje continuo e incluyente en la organización. Montevideo, Uruguay: CINTERFOR/OIT.
Morales, J., y Huici, C. (1989). Lecturas de Psicología Social. Madrid, España: Publicaciones de la UNED.

Moya, M. C. (1999). Persuasión y Cambio de Actitudes. En F. J. Morales Domínguez, M. C. Moya Morales, E. Gaviria Stewart, \& I. Cuadrado Guirado, Psicología Social, (pp. 154-170). México DF, México: Mc Graw Hill.

Navarrete, C. A. (2014). Seguridad Jurídica de los remates judiciales de inmuebles en el Perú (Tesis Doctoral en Derecho y Ciencias Políticas). Universidad Nacional de Trujillo, Perú.

Petty, R., y Cacioppo, J. (1986). The Elaboration Likelihood Model of Persuasion. Advances in Experimental Social Psychology (19), pp. 123-205.

Reeve, J. (2010). Motivación y emoción. México: McGraw-Hill Interamericana.

Robbins, S., y Coulter, M. (2008). Administración. México DF, México: Pearson Educación.

Robbins, S., y Judge, T. (2009). Comportamiento Organizacional. México DF, México: Pearson Educación.

Rodríguez, M. (2004). Psicología del mexicano en el trabajo. México DF, México: Mc Graw Hill.

Sierra B., R. (2001). Técnicas de Investigación Social. Teoría y Ejercicios. Madrid: Paraninfo, Thomson Learning.

Singer, M. (Abril de 2002). Una aproximación a la práctica y la teoría de las Subastas. Abante, 5(1), pp. 3-29.

Tobón, S. (2006). Formación basada en competencias. Bogotá, Colombia: Encoe Ediciones.

Trenholm, S. (1989). Persuasion and social influence. Englewood Cliffs, NJ: Prentice-Hall.

Vasco, A. (2014). Desarrollo Profesional del Abogado como Martillador Público. Tesis para optar el título en Derecho. Quito, Ecuador: Universidad Central de Ecuador.

Vera, J. L. (2016). La eficacia de la decisión del Juez en regular los honorarios del martillero público, en concordancia de la norma procesal (Tesis para optar el grado de título profesional de Abogado). Universidad de Huánuco, Perú. 